\title{
AS RELAÇÕES CULTURAIS E LITERÁRIAS LUSO-BRASILEIRAS EM REVISTA: A IMPORTÂNCIA DE CARLOS MALHEIRO DIAS E A SUA ILUSTRAÇÃO PORTUGUESA (1903-1930)
}

Fernanda Suely Müller ${ }^{1}$

\begin{abstract}
RESUMO: Neste trabalho objetivamos divulgar alguns dados acerca da revista Ilustração Portuguesa e a importância do jornalista lusitano Carlos Malheiro Dias como elemento fundamental e fomentador da cultura portuguesa em periódicos luso-brasileiros no início do século XX, apesar da delicada relação entre Brasil e Portugal nesse período Pré-Moderno. A citada revista pertence ao corpus da pesquisa de Doutorado que estamos realizando com o apoio da FAPESP e que procura responder, entre outras questões, a pertinência dessa manutenção do status quo cultural português almejada por tais intelectuais nessa época.
\end{abstract}

PALAVRAS-CHAVE: imprensa periódica literária luso-brasileira; relações literárias e culturais luso-brasileiras; Portugal; Brasil; Pré-Modernismo brasileiro; Modernismo português.

\begin{abstract}
In this work we intend to show some information about the magazine Ilustração Portuguesa and the importance of the Portuguese journalist Carlos Malheiro Dias as an essential promoter from the Portuguese culture at Brazilians and Portuguese newspapers from the beginning of $20^{\text {th }}$ century, despite of the complicated relations between both countries in that age. The mentioned magazine belongs to the corpus of our Doctorate's research supported by FAPESP that tries to answer, among other things, the pertinence of maintenance of that status quo from this Portuguese culture desired by those intellectuals in that years.
\end{abstract}

KEYWORDS: Literary luso-brazilian periodic press; Luso-brazilian cultural and literary relations; Portugal; Brazil; Brazilian Pré-Modernism; Portuguese Modernism.

\footnotetext{
${ }^{1}$ Doutoranda em Literatura Portuguesa (USP/FAPESP)
} 


\section{Introdução}

No Brasil do início do século XX, observamos que a preocupação pela definição do caráter nacional tinha ligação com as especulações estéticas e/ou poéticas. Com a aproximação do Centenário da Independência (1922), marco histórico em que a sociedade intelectual possivelmente realizaria um balanço da nacionalidade, cresce a discussão e a publicação de obras e estudos sobre a História do Brasil, Educação, Sociologia, Literatura e Língua Nacional.

No caso desses dois últimos elementos, vale notar que segundo Herder (1744-1803), em Idéias para a filosofia da história da humanidade, a linguagem de um povo é o traço mais genuíno do coletivo, de uma comunidade e é o elemento que melhor pode caracterizá-lo enquanto nação. Isso porque, através da linguagem - produto social - os homens transmitem, justificam, explicam ou contestam o mundo e a imagem que dele fazem. Tais fundamentos, indispensáveis ao que concerne à idéia de Pátria - já que a língua é o substrato vivo de uma cultura - foram incorporados pela poética Romântica e, não por acaso, são retomados cerca de um século depois com a polêmica sobre a relação entre língua e nação, que marcou a geração modernista brasileira e a luta para a construção da nossa identidade.

Neste período de transição e de profundas transformações sociais, sobretudo a última década do século XIX e os anos iniciais do século XX, observamos divergências que se traduziam, por um lado, na busca da Modernidade, na renovação e industrialização e, por outro, nas forças que primavam pela permanência de valores tradicionais, como a Monarquia (talvez ainda resquício da passagem da Corte portuguesa pela cidade carioca), no cultivo da cultura e literatura européia, principalmente portuguesa e francesa, e no sustento de uma economia rural baseada em latifúndios e oligarquias.

Apesar de intimamente ligadas, principalmente pela comunhão lingüística, é nesse momento que observamos, no Brasil, ainda a busca da "ruptura" e do desvencilhamento das influências européia e portuguesa, e o "desconhecimento" da expressão literária pelo lado dos intelectuais portugueses, segundo a maior parte dos críticos especialistas no assunto e no período. Porém, como nada é absoluto, ainda mais quando consideramos esse período de intensas mudanças políticas, econômicas e sociais 
dessa sociedade "moderna" que se instalava, há outras perspectivas de importantes críticos, como Arnaldo Saraiva ou João Alves das Neves. Eles defendem um ponto de $v_{\text {vista }}^{2}$ diverso, ou seja: que houve um diálogo muito profícuo entre as intelectualidades brasileira e portuguesa no período, estabelecido especialmente através da imprensa periódica especializada, mas que, no entanto, sendo pouco estudada e discutida, ainda permanece desconhecida e contribui para o reforço das convicções clássicas da grande distância entre as culturas luso-brasileiras na época em tela.

Desse modo, percebemos que muitas revistas portuguesas da época - e mesmo aquelas que se intitulavam luso-brasileiras, para a divulgação da cultura e literatura de e para ambos os países - de forma análoga ao jornal O Estado de São Paulo ${ }^{3}$, utilizavamse de artigos/matérias para realizar a manutenção do status quo português, apesar dos debates intensos acerca da desvinculação cultural promovida por alguns intelectuais brasileiros, por exemplo.

A imprensa de modo geral e, particularmente, as revistas produzidas pela intelectualidade portuguesa constituíram-se em verdadeiros locais privilegiados de discussão acerca da escrita da História, da situação política, social, cultural e econômica de Portugal e das relações com outros países. Transformados em veículos de propagação de idéias nacionalistas, dirigiam-se principalmente para o Brasil, tentando cumprir o papel da imprensa, no sentido em que Pierre Bourdieu a concebe, ou seja: travando sobretudo uma luta política através da produção do conhecimento; buscando o reconhecimento pela produção e reprodução de capital simbólico que expressam notoriedade e respeitabilidade; afirmando sua autoridade e, por conseguinte, impondo ou criando condições para difundir e impor o conhecimento considerado legítimo e verdadeiro do sentido do mundo social, da sua significação atual e da direção em que vai e deve $i r^{4}$.

Nesse contexto, e consoante os estudos prévios realizados por Neves, Saraiva e Serpa, observamos que não constavam estudos sistemáticos sobre as relações culturais e

\footnotetext{
${ }^{2}$ Cf. Arnaldo Saraiva, O modernismo brasileiro e português: subsídio para o seu estudo e para a história das suas relações, Campinas, UNICAMP, 2004 e ainda João Alves das Neves, As relações literárias de Portugal com o Brasil, Lisboa, Icalp, 1992.

${ }^{3}$ Cf. Fernanda Suely Muller, Ruptura ou tradição? A crítica e literatura portuguesa em "O Estado de São Paulo" no Pré-Modernismo brasileiro: 1900- 1911, São Paulo, FFLCH-USP, Dissertação de Mestrado defendida em março/2007, sob a orientação da Profa. Dra. Annie Gisele Fernandes e fomentada pela FAPESP.

${ }^{4}$ Pierre Bourdieu, Meditações Pascalianas, Oeiras, Celta Editora, 1998, p.165.
} 
literárias entre Brasil e Portugal na imprensa periódica da época. De acordo com Saraiva:

A falta desse estudo parece tanto mais grave quanto é certo que o Modernismo português e brasileiro representam sem dúvida os momentos mais altos da cultura portuguesa e brasileira no século XX, e quanto é certo que se supõe comumente que o modernismo brasileiro teorizou e praticou a separação definitiva entre a cultura brasileira e portuguesa, ou que os modernistas brasileiros ignoraram a literatura portuguesa. (SARAIVA, 2004, p.15)

Para constituir o corpus fundamental da pesquisa, além da já citada Ilustração Portuguesa (1903-1924), escolhemos algumas revistas luso-brasileiras, tais como a Atlântida (1915-1920), Os Serões (1901-1911), Brasil-Portugal (1899-1914), etc.

Desde o primeiro contato com as revistas integrantes de nosso corpus, despertou-nos a atenção a maneira como ambos os países foram retratados em tais publicações (que, na maioria das vezes, embora se auto-intitulassem luso-brasileiras, priorizavam, nitidamente, apenas a promoção de Portugal e seus valores). Outra questão que nos intriga ainda é descobrir o verdadeiro propósito de tal aproximação e estreitamento dessas relações pela imprensa periódica, justamente num período em que no Brasil as discussões acerca da construção da identidade nacional se acirravam. Certos de que não poderemos responder a tais perguntas de imediato, discorreremos brevemente acerca da figura do intelectual luso-brasileiro Carlos Malheiro Dias e seu papel como fomentador da cultura portuguesa no Brasil através, principalmente, da revista Ilustração Portuguesa, da qual foi diretor.

\section{A imprensa de ilustração, Carlos Malheiro Dias e sua Ilustração Portuguesa (1903-1930)}

O advento e desenvolvimento da imprensa de ilustração em Portugal, ou seja, o desdobramento da imprensa tradicional em publicações periódicas e ilustradas - e por isso mesmo, mais didáticas que as usuais - e que tinha como um de seus objetivos complementar a educação básica do cidadão médio português, por exemplo, se dá a partir de 1837 aproximadamente, como assinala Sant'Anna ${ }^{5}$. Em sua tese de

\footnotetext{
${ }^{5}$ Benedita de Cássia Sant'Anna, Ilustração Brasileira (1854-1855) e a Ilustração Luso-Brasileira (1856, 1858, 1859): uma contribuição para o estudo da imprensa literária em língua portuguesa, São Paulo, FFLCH-USP, 2007 (Tese de Doutorado em Letras).
} 
Doutoramento, ela investigou esse tipo de imprensa em Portugal, bem como as suas relações com as primeiras publicações ilustradas aqui no Brasil. Ainda nesse estudo, a pesquisadora assinala também, de certo modo, o início dessa tradição das publicações luso-brasileiras que procuravam estreitar os laços entre Brasil e Portugal através da imprensa, observados já desde o período romântico na segunda metade do século XIX, pelo menos.

Consoante tal cenário, e de certa forma um continuador dessa estética de ilustrações, surge a figura de Carlos Malheiro Dias (1875-1941), que foi um importante escritor, jornalista e historiador de seu tempo, mas que hoje é pouco conhecido. Estudou Direito na Universidade de Coimbra, curso que não terminou, e foi eleito deputado em 1897, cargo renovado e posteriormente abandonado em 1910, devido à implantação da República. Foi também sócio da Academia das Ciências, da Academia Brasileira de Letras, membro fundador da Academia Portuguesa de História e diretor da revista Ilustração Portuguesa.

Monárquico, a implantação da República em 1910 levou-o a exilar-se, em 1913, no Brasil, onde já anteriormente vivera e publicara o seu romance de estréia, A Mulata (1896). Da atividade que então desenvolveu, destacam-se a História da Colonização Portuguesa no Brasil (1921-1924), de que saíram três volumes, e a fundação da revista O Cruzeiro.

Em 1935, tendo já regressado a Portugal, foi nomeado embaixador português em Espanha, cargo em que não chegou a tomar posse.

Como escritor, Malheiro Dias está ligado ao Naturalismo, sendo considerado, na sua época, o continuador de Eça de Queirós. Escreveu romances históricos, dramas, contos e ensaios políticos. As suas crônicas jornalísticas, valiosas para o conhecimento da vida da capital na época, encontram-se reunidas nos três volumes de Cartas de Lisboa (1905-1907), que contêm igualmente textos de crítica política e histórica ao regime republicano. Escreveu Filhos das ervas (1900), Os Teles de Albergaria (1901), Paixão de Maria do Céu (1902), O Grande Cagliostro (1905) e A vencida (1907), além de volumes sobre política e textos de conferências. Como dramaturgo, escreveu $A s$ inimigas (1913). 
O jornalista, assim como muitos de seus colegas no jornal O Estado de S. Paulo ${ }^{6}$ nesse período e tantos outros que colaboravam com a imprensa periódica da época, foi um dos inúmeros luso-brasileiros que se empenharam em estreitar os laços culturais entre os dois países nesse período de transição pré-moderno, quando, pelo menos, pressupunha-se uma negação desses laços, que atingiria o ápice nos eventos que marcaram a Semana de Arte Moderna em 1922.

Segundo Vieira:

Com o seu zelo patriótico, Dias começou a investigação histórica com o propósito de glorificar Portugal aos olhos dos brasileiros. Embora Dias tenha expressado a sua admiração pelo Brasil, é bem claro que ele estava imaginando o Brasil como uma plataforma, a partir da qual poderia relançar o Portugal do século XVI, sempre a conquistar novos horizontes. (VIEIRA, 1991, pp. 151-152)

Para atingir seus objetivos, o historiador-jornalista valeu-se principalmente da imprensa e especialmente das revistas das quais foi fundador ou diretor. Além da revista Ilustração Portuguesa, de que falaremos melhor adiante, Dias transformou a revista $O$ Cruzeiro, a partir de 1917, em "o porta-voz da colônia portuguesa no Brasil"”, bem como a Revista da Semana, publicada no Rio de Janeiro, a partir de 1915. O jornalista também colaborara esporadicamente nas revistas modernistas Seara Nova e Atlântida, e igualmente se empenhara em divulgá-las no Brasil.

A citada revista Ilustração Portuguesa foi, segundo o próprio subtítulo, uma "revista semanal dos acontecimentos da vida portuguesa, vida social, vida política, vida artística, vida literária, vida mundana, vida esportiva e doméstica". Publicada em Lisboa, foi propriedade do jornal português $O$ Século, e circulou entre 1903 a 1930, dividida em duas séries. A $1^{\text {a }}$. série, luxuosamente impressa, veio a lume de 9 de novembro de 1903 a 12 de novembro de 1906, totalizando 119 números, sob a direção de José Joubert Chaves. Nesta primeira fase, apresentou fotografias de personalidades de vulto da cultura portuguesa, como Eça de Queirós e Oliveira Martins, e crônicas regulares de Rocha Martins. A 2a . série foi publicada entre final de 1906 a 6 de março de 1930, agora sob a direção de Carlos Malheiro Dias, num total de 959 edições. Constituindo um relevante acervo do quotidiano do primeiro quartel do século $\mathrm{XX}$, foi o

\footnotetext{
${ }^{6}$ Cf. Fernanda Suely Muller, op.cit.

${ }^{7}$ VIEIRA, Op. Cit., p.151
} 
veículo, por exemplo, de poemas de Fernando Pessoa (“Canção de Outono" e "Canção") e um profundo dossiê dedicado a Teófilo Braga no primeiro número da segunda série. Teve como colaboradores literários: Alberto Teles, Albino Forjaz de Sampaio, António Sardinha, Aquilino Ribeiro, Bulhão Pato, Câmara Reis, Carlos Malheiros Dias, Eugênio de Castro, Fernando Pessoa (revistas números 832,834), Gago Coutinho, Jaime Cortesão (números 198, 378, 422, 828, 843), João de Barros, Júlio Dantas, Manuel da Silva Gaio, Rocha Martins, Stuart Carvalhais, entre outros.

É interessante notar como a revista foi amplamente divulgada nas páginas do jornal OESP a partir de 1906 (quando Dias assume a sua direção), assim como os planos que a redação da gazeta e o jornalista fizeram para o lançamento de uma futura revista que estreitaria ainda mais os laços culturais Brasil-Portugal no período.

Vejamos, por exemplo, como foi a repercussão da visita de Carlos Malheiro Dias ao Brasil em meados de 1907 retratada pelo jornal O Estado de São Paulo, e a constante reiteração da idéia de se divulgar a cultura e valores portugueses no Brasil:

Como tivemos ocasião de noticiar, a vinda ao Brasil, do talentoso escritor português Sr. Carlos Malheiros Dias, tem como principal objetivo transformar a sua excelente revista "Ilustração Portuguesa", em um grande magazine literário brasileiro e português. Essa transformação obedeceria a dois intuitos principais: primeiro - o de aproximar e quase unificar as duas literaturas (...) reatando assim a comunidade literária que perdurou até aos primeiros anos do século XIX, e definitivamente integrando na literatura brasileira toda a tradição clássica portuguesa, pois que em nenhuma esfera da atividade intelectual, mais do que na literatura, a despeito de todas as modalidades e diferenciações provocadas pelas condições naturais e sociais do meio, essa unidade se impõe, tratando-se de uma atividade mental exercida na mesma 'matéria-prima': o idioma. Para concorrer proficuamente a essa hegemonia literária, a Ilustração Portuguesa alteraria seu título, passando a chamar-se Ilustração Brasileira e Portuguesa; estabeleceria no Rio de Janeiro uma grande sucursal (...) Cada número semanal da grande revista seria o orgulhoso atestado intelectual da raça que se agita nos cinco continentes, e que se pode corresponder na mesma linguagem de Macau para o Amazonas, de Lisboa para o Rio de Janeiro, de Gôa para Bahia, de Timor para o Paraná, de Coimbra para São Paulo [...] E esta permuta incessante de imaginação e erudição, provocando a intimidade entre as maiores mentalidades dos dois povos, e concorrendo poderosamente para a manutenção da susserania mental da raça no seu constante convívio com raças díspares, prodigiosamente concorreria, como surpreendente estímulo, para o desenvolvimento das ciências e das artes. A produção literária atingiria pela primeira vez nos dois países uma difusão enorme. Cada romancista, cada poeta, cada economista, cada sociólogo teria, enfim, alcançado um público imenso. Quase 
simultaneamente, as suas obras seriam assimiladas nos cinco continentes. (BRASIL - Portugal, 1907, p. 01)

Neste excelente editorial, alguns termos como "quase unificar", "reatar uma comunidade literária", "integrar na literatura brasileira a tradição clássica portuguesa", "hegemonia literária" e "susserania mental da raça" emergem gritantes como demonstração de uma supremacia da cultura portuguesa, à qual o Brasil deveria se subordinar para atingir certo nível de reconhecimento literário ao incorporar a tradição e o modelo na busca de uma utópica unidade. O editor, ao promover a revista Ilustração Portuguesa, reforça com toda a clareza a manutenção do status quo dos valores portugueses através da língua e da literatura, e consoante alguns indícios desse propósito que já tínhamos apontado anteriormente. Notemos que as particularidades brasileiras, bem como a sua comunidade literária e lingüística - já que o português brasileiro recebera importantes influências de outros povos que constituíram o país, como o negro e o índio - foram completamente ignoradas. Imediatamente recordamos de Herder, mencionado no início deste artigo, principalmente quando o filósofo, no início do século XIX, e no momento crucial para a formação das identidades das nações, acrescenta ser a linguagem o traço mais genuíno de uma sociedade, e o elemento que melhor pode caracterizar e diferenciar um país das outros, além da unidade territorial e das características comuns que determinam um povo. Neste contexto, toda a individualidade brasileira é brutalmente suprimida em prol de uma almejada comunidade cultural luso-brasileira, preocupada em cultivar e manter acesos os valores do colonizador, tidos como superiores, nas ex-colônias, através da linguagem.

No artigo intitulado Coisas estrangeiras de 02 de setembro de 1907, publicado também no jornal OESP, Oliveira Lima disserta sobre Carlos Malheiro Dias e o reforço do projeto luso-brasileiro para os laços culturais entre ambos os países:

Regressou há pouco para Portugal o Sr. Carlos Malheiro Dias e se não logrou converter numa realidade o seu formoso e grandioso plano de solidariedade das duas literaturas de língua portuguesa, desenvolvendo-se cada uma na esfera particular que lhe constituem suas condições e aspirações, mas tornando-se bem conhecidas e amigas como cumpre ao seu próximo parentesco, deve pelo menos ter levado, além da sensação das simpatias pessoais que deixou, a impressão de que a sua viagem não foi em todo o caso improfícua ao nobre fito que aqui o trouxe. [...] O seu plano, os leitores do "Estado" 
o conhecem bem, porque ele o explicou nestas colunas com muita clareza, muita eloqüência e a mesma vivacidade que costuma pôr na conversa e que estabelece uma perfeita correspondência entre o seu estilo ágil e a sua fisionomia expressiva, na qual a doçura do olhar corrige a ironia do sorriso e ambas completam as linhas de uma curiosidade inteligente. (p.1)

Mais uma vez, é o brasileiro Oliveira Lima que endossa o "plano" dos portugueses e ainda o discurso do redator do OESP no artigo sobre a revista Ilustração Portuguesa, sobre a qual já discorremos. Lima, além de discorrer longamente sobre as qualidades do escritor, ao afirmar que

(...) devaneará reatar a comunidade literária de outrora em benefício recíproco das duas nacionalidades, cujos laços econômicos são presentemente mais fortes do que os intelectuais, e que por todos os momentos ganhariam em assentar a sua aproximação moral sobre a base que lhes pertence igualmente, pois que lhes é fornecida pela identidade do idioma,

justifica ainda tal propósito de "interação" argumentando que para o Brasil é necessário a presença e o modelo português:

Se ao Brasil literário convém não deixar perder a tradição clássica portuguesa, que lhe empresta um passado, uma história e um modelo, ao Portugal literário cabe não permanecer indiferente àquela expressão da antiga colônia, que ao mesmo tempo e as circunstâncias têm vindo diferenciando, mas lhe é devedora da sua primeira educação e mesmo, nos tempos modernos, de poderosas sugestões.

Convencido realmente desse escopo, Lima comenta ainda que a revista citada,

(...) instrumento dessa união, abrangia na prática uma variedade de aplicações, de trocas de visitas literárias, de exposições de arte, de conferências, de exibições musicais e oratórias, que podem ser irrealizáveis de momento, isto é, de um momento para o outro, mas que no futuro se hão de realizar, quando a cultura aqui for mais disseminada e lá mais proselitica (sic).

Ou seja, através de uma falsa relação dialética, intelectuais luso-brasileiros como Dias pretendiam utilizar mais um instrumento de divulgação da cultura portuguesa, isto é, a revista, além, é claro, do próprio jornal OESP engajadíssimo nesse propósito, como já pudemos perceber. 
No final do citado artigo, Lima explica os motivos que movem Dias e seus compatriotas neste plano de aproximação cultural e ainda disserta sobre a importância da tradição, a mesma que eles insistentemente tentaram amalgamar com a realidade brasileira, na constituição de uma sociedade:

(...) Este portuguesismo só tem feito crescer com a aplicação e o estudo, ainda que jamais se tornando enfadonho ou irritante. É um nacionalismo por assim dizer intelectual, feito da consciência do passado pela sua aquisição mental e da confiança do futuro pelo seu instinto agudo. [...] Os fidalgos distinguem-se dos rastaqueres pela educação ainda mais do que pelo nascimento, o fidalgo tem que ser no escrever quem lida a cada instante com a sentimentalidade de outrora, quem tanto admira as glórias, as virtudes e tanto atenua os crimes, as vergonhas das eras donde decorre a tradição, que é o sistema nervoso de um organismo social. Penso que a minha imediata simpatia pelo sr. Malheiro Dias despertou-a mais que tudo - mais do que a sua extrema cortesia, mais do que a seu entranhado afeto à profissão literária, tão nobre - essa sua ternura da qual compartilho pelo que praticaram de bom e de útil, de interessante e de grande as gerações mortas, os nossos antepassados, porque todos os temos. (p.1)

Destarte e, pensando ainda nesse período moderno que representou uma espécie de "amadurecimento" da literatura brasileira, gostaríamos de refletir sobre o papel dessa imprensa periódica no referido contexto.

Não deixa de ser estranho como as revistas que fomentavam o luso-brasileirismo conseguiram sobreviver e propagar esse ideal da luso-brasilidade e de estreitamento das relações culturais entre os países (desde, é claro, que se sobressaíssem os valores portugueses, não podemos nos esquecer) em um período tão impertinente para tais discussões, e, praticamente, concomitante aos acontecimentos que se tornariam um marco para a cultura e literatura nacionais em 1922.

Se no início tal afirmação pode parecer estranha e contraditória em si mesma afinal, as revistas citadas pregavam a aproximação luso-brasileira através, sobretudo, da valorização da cultura/raízes portuguesas imbuídas na constituição do país e que, justamente, representou um dos alvos de crítica dos Manifestos Modernistas lembremos que, não por acaso, o período foi marcado por um contínuo dialético de tradição e ruptura que, mesmo com a explosão da Semana de 22, não conseguiu extirpar a presença indelével de Portugal, seja através da língua, pelo amadurecimento que proporcionou tais reflexões em busca da identidade brasileira ou ainda pelo belo galho 
que criamos, parodiando a gênese criacionista da nossa literatura exposta por Antônio Cândido na famosa Formação.

Conscientes ainda de que não existe escrita neutra, e de que toda a fala é uma estratégia política, na medida em que o emissor sempre tenta convencer seu interlocutor pelo seu ponto de vista, sabemos que tal discussão não se encerra aqui, e que todas as variantes que permeiam esse discurso devem ser analisadas para que possamos ter um estudo realmente consistente. Desse modo, esperamos que, com a conclusão da pesquisa de Doutorado que estamos realizando, possamos responder pelo menos algumas das inúmeras perguntas já levantadas com a leitura prévia do corpus. Assim, pretendemos ainda traçar um perfil que atenda às especificidades desse momento importante para a história e para a literatura nacionais e que contribua para uma melhor compreensão das verdadeiras relações luso-brasileiras no período.

\section{Referências bibliográficas}

ABDALA JÚNIOR, Benjamin (org). Incertas relações: Brasil-Portugal no século XX. São Paulo: SENAC, 2003.

BRASIL-Portugal, O Estado de São Paulo, 9 de julho de 1907, p.1

BOUDIEU, Pierre. (Trad. Sergio Miceli) A economia das trocas simbólicas. São Paulo: Perspectiva, 2005. . Meditações Pascalianas. Oeiras: Celta Editora, 1998.

CANDIDO, Antônio. Formação da literatura brasileira. Belo Horizonte: Ed. Itaiaia, 1981.

LIMA, Oliveira. Coisas estrangeiras: O Sr. Carlos Malheiro Dias. O Estado de São Paulo, 02 de setembro de 1907, p.1.

MULLER, Fernanda S. Ruptura ou tradição? A crítica e literatura portuguesa em "O Estado de São Paulo” no Pré-Modernismo brasileiro: 1900 - 1911. São Paulo: FFLCH-USP, 2007 (Dissertação de Mestrado em Letras).

NEVES, João Alves das. As relações literárias de Portugal com o Brasil. Lisboa: Icalp, 1992.

PIRES, Daniel. Dicionário das revistas literárias portuguesas do século XX. Lisboa: Contexto, 1986. 
SANT'ANNA, Benedita de Cássia Lima. Ilustração Brasileira (1854-1855) e a Ilustração Luso-Brasileira (1856, 1858, 1859): uma contribuição para o estudo da imprensa literária em língua portuguesa. São Paulo: FFLCH-USP, 2007 (Tese de Doutorado em Letras).

SARAIVA, Arnaldo. O modernismo brasileiro e português: subsídios para o seu estudo e para a história das suas relações. Campinas: UNICAMP, 2004

SERPA, Élio. Portugal no Brasil: a escrita dos irmãos desavindos. Rev. bras. Hist., São Paulo, v. 20, n. 39, 2000. Disponível em: <http://www.scielo.br/scielo.php? script=sci_arttext\&pid=S010201882000000100004\&lng=en\&nrm=iso $>$. Acesso em: 03 Apr 2007. Pré-publicação. doi: 10.1590/S0102-01882000000100004

VIEIRA, Nelson H. Brasil e Portugal: a imagem recíproca - o mito e a realidade na expressão literária. Lisboa: Ministério da Educação; Instituto da Cultura e Língua Portuguesa, 1991. 